\title{
Controlling wasteloads from point and nonpoint sources to river system by GIS-aided Epsilon Robust Optimization model
}

\section{$\operatorname{AUTHOR}(S)$ :}

Maeda, Shigeya; Kawachi, Toshihiko; Unami, Koichi; Takeuchi, Junichiro; Ichion, Eiji

\section{CITATION:}

Maeda, Shigeya ...[et al]. Controlling wasteloads from point and nonpoint sources to river system by GIS-aided Epsilon Robust Optimization model. Journal of Hydro-environment Research 2010, 4(1): 27-36

\section{ISSUE DATE:}

2010-04

URL:

http://hdl.handle.net/2433/128861

\section{RIGHT:}

(C) 2009 International Association for Hydro-environment Engineering and Research, Asia Pacific Division Published by Elsevier B.V.; この論文は出版社版でありません。引用の際 には出版社版をご確認ご利用ください。; This is not the published version. Please cite only the published version. 


\title{
Controlling wasteloads from point and nonpoint sources to river system by GIS-aided epsilon robust optimization model
}

Shigeya Maeda ${ }^{1 *}$, Toshihiko Kawachi ${ }^{1}$, Koichi Unami $^{1}$, Junichiro Takeuchi ${ }^{1}$ and Eiji Ichion ${ }^{2}$

${ }^{1}$ Graduate School of Agriculture, Kyoto University, Kitashirakawa Oiwake-cho, Sakyo-ku, Kyoto, 606-8502 Japan

${ }^{2}$ Faculty of Bioresources and Environmental Sciences, Ishikawa Prefectural University, 1-308 Suematsu, Nonoichi-cho, Ishikawa-gun, Ishikawa, 921-8836 Japan

*Corresponding author. E-mail address: smaeda@kais.kyoto-u.ac.jp

\begin{abstract}
A stochastic multiobjective programming model, an $\varepsilon$-RO (Epsilon Robust Optimization) model as a simulation-optimization model with an embedding approach, is developed for river water quality management under hydro-environmental uncertainty. The model is a hybrid of the $\varepsilon$-constraint method and the robust optimization framework, which depresses the high sensitivity of the model to the input data uncertainties by introducing a plausible set of scenarios. Possible pollutant sources (all kinds of point and nonpoint pollutant sources excepting forests) are treated as controllable. The finite element method is employed for approximations to COD (Chemical Oxygen Demand) and DO (Dissolved Oxygen) transport equations with convection and dispersion terms. Realizations for the in-stream COD-DO interactive events, thus described in discrete forms, are embedded as equality constraints in the model. Controlling wasteloads from a variety of sources is implemented by seeking noninferior solutions (management alternatives) that maximize total COD load to the stream while minimizing COD load deviations and in-stream water quality violations. Demonstrative operation of the model is made with its application to the Yasu River, Japan. It is shown that there is indeed an alternative management strategy to improve in-stream water quality as a whole while increasing the total allowable load to the stream. The $\varepsilon$-RO model developed could thus be a viable alternative to the conventional river water quality management models.
\end{abstract}

Keywords: Optimization; Nonpoint pollutant source; Domestic wastewater; River water quality management; Uncertainty; Geographic Information System 


\section{Introduction}

Reconciling human activities with river water quality conservation is one of the major requirements for sustainable economic and social development. As an overarching theme of this reconciliation, scientific approaches to basin-scale river water quality management problems have been made using a mathematical programming technique which is capable of harmonizing the competing goals of stakeholders under hydro-environmental, political and institutional constraints. Since rivers are the major source of water used for irrigation and drinking in Japan, river water quality control is of vital importance.

Problem formulations have commonly been made to minimize wastewater treatment levels (or costs) in compliance with given in-stream water quality standards (WQSs). For example, Ejaz and Peralta (1995) proposed a simulation-optimization (S/O) model for showing the trade-off between human and bovine populations from which treated wastewater can be discharged into the river system, and solved this multiobjective programming problem by use of the $\varepsilon$-constraint method. Uncertainty of inflow rates at the upstream end of a river was taken into account through obtaining different sets of noninferior solutions with different inflow rates. As part of the optimization constraint sets, the assimilative capacities of a stream for a variety of water quality constituents including BOD (Biological Oxygen Demand) were represented by the regression equations obtained from numerous external simulations [i.e., by a regression approach (Alley, 1986)]. Chang et al. (1997) presented the interactive fuzzy interval multiobjective programming model which was capable of determining wastewater treatment levels within a river basin that would minimize total treatment cost and yet maximize BOD loading to the river while considering the uncertainties of a decision maker's preference. Mass balances representing pollutant and flow continuities in streams were embedded in the model as equality constraints (i.e., by an embedding approach in S/O models), the former being derived by successively applying the classic Streeter-Phelps equation from upstream to downstream river segments. Takyi and Lence (1999) developed an approach for evaluating the trade-off between wastewater treatment cost (for BOD removal) and reliability of achieving pollution control (i.e., dissolved oxygen (DO) objectives) under input information uncertainties of stream velocity, stream temperature and reaeration rate, using a multiple-realization chance constraint method. Using the random values of the uncertainties generated by Monte Carlo simulation, the realizations associated with DO improvements per unit waste removed by each discharger were produced based on the Camp-Dobbins modification to the Streeter Phelps equation. This is an application of not true but pseudo-embedding approach. Mujumdar and Sasikumar (2002) presented an approach which could consider uncertainties due to randomness of river flow and fuzziness in the management goals of simultaneously achieving as low risk as possible of low water quality and as minimum fractional BOD removal level as possible, in order to obtain seasonal 
fractional BOD removal levels in terms of which DO deficits at checkpoints in a river, confined within a given range, are expressed using the Streeter-Phelps equation.

Alternative formulations addressing the objective in terms of wasteload in lieu of treatment level or cost are rather primitive, but rare in practice. Without consideration of uncertainties and also of mass balances for flow and water quality constituents in streams, Hathhorn and Tung (1989) solved a bi-objective problem to maximize BOD discharge and minimize the largest difference in equity measures between various waste dischargers using fuzzy linear programming. Jia and Culver (2006) developed a robust optimization model to incorporate the uncertainty of water quality predictions and to minimize pollutant load reductions (fecal coliform bacteria) given various levels of reliability with respect to WQSs. The water quality predictions were generated and linked to the optimization algorithm using the linear response matrix that could be obtained from an external hydrological simulation model which performs flow routing and simulates in-stream water quality processes. The approach employed is categorized as a linking approach. The true embedding approach where numerical discrete forms of flow and transport equations are included as constraints in optimization models has commonly been used for groundwater management (Gorelick and Remson, 1982; Gharbi and Peralta, 1994; Peralta et al., 1994). The first application to surface water pollutant transport was made by Kawachi and Maeda (1999) in which coupled steady-state BOD and DO transport equations of complete form were approximated by the finite element method to embed them as equality constraints in the deterministic optimization model for BOD load allocations to point sources (PSs/industrial wastewater treatment plants) within a river basin. The coefficients of the transport equations were also estimated by numerically solving the gradually-varying steady-state flow equation by the finite element method. Building on this work, Maeda et al. (2000) and Kawachi and Maeda (2000) developed scenario-based stochastic robust optimization (RO) models within the general framework of robust optimization theory (Mulvey et al., 1995) to produce solutions insensitive to the input data uncertainties as found in stream flow rate or water depth. To obtain a scalar objective function, the prime objective of maximizing the expected total BOD load to the river was penalized by two different weighted objectives, associated with solution robustness and model robustness, which control the total BOD load deviations and the water quality violations, respectively. This RO model was reformulated as an epsilon robust ( $\varepsilon-\mathrm{RO})$ optimization model by introducing the $\varepsilon$-constraint method which takes only the prime objective as an objective function, and moves other objectives to constraints (Maeda and Kawachi, 2001). The $\varepsilon$-RO model has the additional advantages, arising from the $\varepsilon$-constraints, of producing only such noninferior (or Pareto optimal) solutions as are worthy of discussion in a multiobjective decision-making process and providing trade-off rates among objectives of each noninferior solution (Chankong and Haimes, 1983). From due cognizance of its lesser applicability to the real 
world, nonpoint source (NPS) pollutant loading from agriculture, assumed to be uncontrollable, was incorporated in the $\varepsilon$-RO model, and thereby BOD load was replaced by $\mathrm{COD}_{\mathrm{Mn}}$ load (Chemical Oxygen Demand (permanganate oxidizability), hereinafter noted as COD) as a decision variable since unit area loading from agricultural lands is measured by COD rather than by BOD and the water quality indicator for a river should be commensurable with that for a lake in dealing with a river-lake composite system (Kawachi and Maeda, 2004a). The model so modified was used for generating noninferior solutions against which the current water quality and pollution control policy in the Yasu River, which communicates with Lake Biwa, Japan, could be appraised diagnostically (Kawachi and Maeda, 2004b).

This paper builds on the work of Kawachi and Maeda (2004b) where pollutant sources such as domestic septic tanks and community wastewater treatment plants have not been treated as pollutant sources because of the difficulty of collecting associated data. However, those sources are considered to seriously affect river water quality as they occupy a significant portion of total loads from urban and residential areas. A geographic information system (GIS) is employed to store and manage spatial data on such pollutant sources in this study, resulting in consideration of all the PSs and NPSs. After significant modifications of the objective function and constraints, a modified $\varepsilon$-RO model is again applied to the Yasu River to demonstrate its capability of producing significant noninferior solutions as well as to find effective wasteload allocation alternatives for improving in-stream water qualities.

\section{COD and DO Transport Equations}

Consider a river or a network of streams with a middle- or large-scale catchment. Water and pollutants are assumed to enter and leave the river laterally through outlets located along the river. Interaction between the stream water and groundwater is assumed negligible.

The COD loading to the river can be categorized as either controllable or uncontrollable. The quality and quantity of runoff water from forests or forested areas are regarded as uncontrollable. The qualities (COD concentrations) of effluents from the possible pollutants sources related to human activities are treated as controllable. Such sources are classified into three types: individually treated PS (ITPS), collectively treated PS (CTPS) and controllable nonpoint source (CNPS), as shown in Fig. 1. Industrial wastewater treatment plants, public sewage treatment plants and night soil treatment facilities are referred to as ITPS since in general their locations are exactly known and thus the wasteloads from them can be treated individually. On-site domestic septic tanks (i.e., integrated treatment tanks (ITTs) and single treatment tanks (STTs)) as well as community 
wastewater treatment plants of point source, too dispersed to identify their exact locations, are collectively treated for the individual subdivided catchments (subcatchments) of the river that can be delineated by use of a Digital Elevation Model (DEM). CNPS containing agricultural lands, cities and golf links, as well as forests of NPS, are also treated for the individual subcatchments. Optimization is to seek allowable limits of COD concentrations of wastewaters discharged from PSs and CNPSs to the river for the fixed discharges of the corresponding wastewaters while meeting water quality requirement in river streams.

It is assumed that all the effluents from ITPSs, CTPSs, CNPSs and forests arrive at the outlets (i.e., loading points) of the subcatchments where the respective sources exist without any change in quality and quantity.

Instead of a local equation, such as the commonly used classic or modified Streeter-Phelps equation, the following coupled one-dimensional steady-state distributed equations with convection and dispersion terms are employed for embedding realizations with respect to in-stream interactive COD and DO (Dissolved Oxygen) transport events in the $\varepsilon-\mathrm{RO}$ model as equality constraints.

$Q \frac{d L}{d x}-\frac{d}{d x}\left(A D_{x} \frac{d L}{d x}\right)+A K_{1} L+\left(\sum_{k} \overline{q_{k}^{p}}+\sum_{X} \overline{q^{p v X}}+\overline{q^{c n p}}+\overline{q^{f}}-\overline{q^{m}}\right) L$
$-\sum_{k} \overline{q_{k}^{p}} L_{k}^{p}-\sum_{X} \overline{q^{p v X}} L^{p v X}-\overline{q^{c n p}} L^{c n p}=\overline{q^{f}} L^{f}$

$Q \frac{d C}{d x}-\frac{d}{d x}\left(A D_{x} \frac{d C}{d x}\right)+A K_{1} L-A K_{2}\left(C_{S}-C\right)$

$+\left(\sum_{k} \overline{q_{k}^{p}}+\sum_{X} \overline{q^{p v X}}+\overline{q^{c n p}}+\overline{q^{f}}-\overline{q^{m}}\right) C=0$

where the superscripts $p, p v X$, cnp and $f$ denote ITPS, CTPS $X$ ( $X$ represents the type of CTPS: $X=1$ for ITTs, $X=2$ for STTs, and $X=3$ for community treatment plants), CNPS and forest, respectively; the superscript $m$ denotes lateral outflow by water withdrawal from the river; the subscript $k$ denotes the identification number of each ITPS; $x=$ horizontal distance along the river $(\mathrm{L}) ; Q=$ cross-sectional discharge $\left(\mathrm{L}^{3} / \mathrm{T}\right) ; A=$ cross-sectional area $\left(\mathrm{L}^{2}\right) ; L$ and $C=\mathrm{COD}$ and $\mathrm{DO}$ concentrations in river stream, respectively $\left(\mathrm{M} / \mathrm{L}^{3}\right) ;\left(L_{k}^{p}, \overline{q_{k}^{p}}\right),\left(L^{p v X}, \overline{q^{p v X}}\right),\left(L^{c n p}, \overline{q^{c n p}}\right)$ and $\left(L^{f}\right.$, $\left.\overline{q^{f}}\right)=\left(\mathrm{COD}\right.$ concentration $\left(\mathrm{M} / \mathrm{L}^{3}\right)$, discharge per unit width $\left.\left(\mathrm{L}^{2} / \mathrm{T}\right)\right)$ of laterally injected wastewaters originating from ITPSs, CTPSs, CNPSs and forests, respectively; $\overline{q_{k}^{f}}=$ laterally withdrawn discharge per unit width $\left(\mathrm{L}^{2} / \mathrm{T}\right) ; D_{x}=$ longitudinal dispersion coefficient $\left(\mathrm{L}^{2} / \mathrm{T}\right) ; K_{1}=$ 
deoxygenation coefficient $(1 / \mathrm{T}) ; K_{2}=$ reaeration coefficient $(1 / \mathrm{T})$; and $C_{S}=$ saturation value of DO $\left(\mathrm{M} / \mathrm{L}^{3}\right)$.

Eqs. (1) and (2) are transformed into algebraic forms by the finite element method (FEM). To prevent numerical disturbances caused by convention-dominant transport, the upwind FEM scheme with unsymmetrical weighting functions expressed in terms of the local Peclet number is used (Unami et al., 1996).

The hydraulic parameters $Q$ and $A$ in Eqs. (1) and (2) need to be determined by flow analysis before discretizing the equations. Since temporal variations of these parameters in a management period are expressed by assuming multiple scenarios, flow analysis should be conducted under every scenario in advance, i.e., with various sets of boundary conditions of upstream discharge and downstream water depth and inflows and outflows in the river. For example, by numerically solving continuity and momentum equations for the steady-state gradually-varying flow equations by FEM and the finite volume method (FVM), respectively, $Q$ and $A$ in Eqs. (1) and (2) can be predetermined subject to appropriate boundary conditions (Unami, 1998; Kawachi and Maeda, 2004a).

\section{Optimization Model}

The $\varepsilon-\mathrm{RO}$ model is capable of providing a maximum allowable COD load for each controllable pollutant source or subcatchment, developed by taking $L_{k}^{p}, L^{p v X}$ and $L^{c n p}$ as decision variables. Hydraulic and hydrological uncertainties of the riverine environment are described by scenarios and their occurrence probabilities which can be provided by stochastic analysis of the historic records concerned. Considering that inter-monthly uncertainties over a year are of primary importance in the context of river water quality management, one scenario is provided for each month. The probability of a scenario can then be defined as the ratio of the monthly number of days to the yearly number of days. Key components of the scenario are $Q, L$, and $C$ at the upstream end of a river, $h$ at the downstream end of a river, $q_{j}^{c n p}\left(j=\right.$ identification number for subcatchments), $T, K_{1}$ and $K_{2}$. Employing such a scenario-based description to produce noninferior solutions robust against the uncertainties and reducing a linear vector (or multiobjective) problem to a scalar (or single-objective) one by introduction of the $\varepsilon$-constraint method (Chankong and Haimes (1983)) yields the complete $\varepsilon$-RO model;

Minimize $f_{1}$

(i) COD and DO transport equations cast into the finite element versions at all scenarios 
$\mathbf{E}_{s} \mathbf{L}_{s}+\mathbf{F}_{s}^{p} \mathbf{L}_{s}^{p}+\sum_{X} \mathbf{F}_{s}^{p v X} \mathbf{L}_{s}^{p v X}+\mathbf{F}_{s}^{c n p} \mathbf{L}_{s}^{c n p}=\mathbf{b}_{s}, \quad \forall s$

$\mathbf{G}_{s} \mathbf{C}_{s}+\mathbf{H}_{s} \mathbf{L}_{s}=\mathbf{d}_{s}, \quad \forall s$

(ii) WQSs at loading points and/or stream junctions in the river at all scenarios

$\mathbf{L}_{s}^{o}-\mathbf{L}_{s}^{o u}=\mathbf{U}_{s}^{o+}-\mathbf{U}_{s}^{o-}, \quad \forall s$

$\mathbf{C}_{s}^{o l}-\mathbf{C}_{s}^{o}=\mathbf{V}_{s}^{o+}-\mathbf{V}_{s}^{o-}, \quad \forall s$

(iii) Water quality limitations at the downstream end of the river at all scenarios

$L_{s}^{d} \leq L_{s}^{d u}, C_{s}^{d} \geq C_{s}^{d l}, \quad \forall s$

(iv) Effluent limitation standards for wastewaters from ITPSs and CTPSs at all scenarios

$\mathbf{L}_{s}^{p l} \leq \mathbf{L}_{s}^{p} \leq \mathbf{L}_{s}^{p u}, \quad \forall s$

$\mathbf{L}_{s}^{p v X l} \leq \mathbf{L}_{s}^{p v X} \leq \mathbf{L}_{s}^{p v X u}, \quad \forall s, X$

(v) Limits for the rates of optimal to current CNPS-born COD loads at subcatchment outlets

$r^{c n p l} \leq \frac{\sum_{s} p_{s} q_{j s}^{c n p} L_{j s}^{c n p}}{L O_{j}^{c n p}} \leq r^{c n p u}, \quad \forall j$

(vi) Lower limits for expected total ITPS- and CTPS-born COD loads

$\sum_{s} p_{s}\left(\sum_{k} q_{k}^{p} L_{k s}^{p}\right) \geq L O^{p l}$ 
$\sum_{s} p_{s}\left(\sum_{j} q_{j}^{p v X} L_{j s}^{p v X}\right) \geq L O^{p v X l}, \quad \forall X$

(vii) Lower limit for expected total CNPS-born COD load

$\sum_{s} p_{s}\left(\sum_{j} q_{j s}^{c n p} L_{j s}^{c n p}\right) \geq L O^{c n p l}$

(viii) $\varepsilon$-constraints

$f_{j} \leq \varepsilon_{j}, \quad j=2,3,4$

(ix) Supplementary constraints at all scenarios in order to make the problem tractable

$y_{s}^{+}-y_{s}^{-}=x_{s}-\sum_{s} p_{s} x_{s}, \quad \forall s$

$p_{s}\left(y_{s}^{+}+y_{s}^{-}\right)-w \leq 0, \quad \forall s$

(x) Nonnegativity at all scenarios

$\mathbf{L}_{s}, \mathbf{L}_{s}^{p}, \mathbf{L}_{s}^{p v X}, \mathbf{L}_{s}^{c n p}, \mathbf{L}_{s}^{o}, L_{s}^{d}, \mathbf{C}_{s}, \mathbf{C}_{s}^{o}, C_{s}^{d}$,

$w, y_{s}^{+}, y_{s}^{-}, \mathbf{U}_{s}^{o+}, \mathbf{U}_{s}^{o-}, \mathbf{V}_{s}^{o+}, \mathbf{V}_{s}^{o-} \geq 0 \quad \forall s, X$

with the definitions;

$f_{1}(\cdot)=-\sum_{s} p_{s} x_{s}$

$f_{2}(\cdot)=\max _{s}\left\{p_{s}\left|x_{s}-\sum_{s} p_{s} x_{s}\right|\right\}$ 
$f_{3}(\bullet)=\sum_{s} \sum_{i} p_{s}\left(U_{i s}^{o+}+V_{i s}^{o+}\right)$

$f_{4}(\cdot)=\sum_{s} \sum_{i} p_{s}\left(U_{i s}^{o-}+V_{i s}^{o-}\right)$

$x_{s}=\sum_{k} q_{k}^{p} L_{k s}^{p}+\sum_{X} \sum_{j} q_{j}^{p v X} L_{j s}^{p v X}+\sum_{j} q_{j s}^{c n p} L_{j s}^{c n p}$

where the superscripts $u, l$ and $o$ stand for upper limit, lower limit, and loading point and/or stream junction, respectively; the subscript $s$ represents scenario; $x_{s}=$ total controllable COD load to the river $(\mathrm{M} / \mathrm{T}) ; p_{s}=$ probability of scenario $s ; q_{k}^{p}, q_{j}^{p v X}$ and $q_{j s}^{c n p}=$ lateral discharges to the river which transport the loads from $k$ th ITPS, CTPS in $j$ th subcatchment and CNPS in $j$ th subcatchment, respectively $\left(\mathrm{L}^{3} / \mathrm{T}\right) ; \mathbf{L}_{s}$ and $\mathbf{C}_{s}=$ vectors of in-stream nodal COD and DO concentrations, $L_{j s}\left(\mathrm{M} / \mathrm{L}^{3}\right)$ and $C_{j s}\left(\mathrm{M} / \mathrm{L}^{3}\right)$, respectively; $\mathbf{L}_{s}^{p}=$ vector of COD concentration of effluent from $k$ th ITPS, $L_{k s}^{p}$ $\left(\mathrm{M} / \mathrm{L}^{3}\right)$ (decision variable); $\mathbf{L}_{s}^{p v X}=$ vector of COD concentration of collected effluent from CTPS $X$ flowing to the outlet of $j$ th subcatchment, $L_{j s}{ }^{p v X}$ (decision variable); $\mathbf{L}_{s}{ }^{c n p}=$ vector of COD concentration of effluent from CNPS flowing to the outlet of $j$ th subcatchment, $L_{j s}{ }^{c n p}\left(\mathrm{M} / \mathrm{L}^{3}\right)$ (decision variable); $\mathbf{E}_{s}, \mathbf{G}_{s}$ and $\mathbf{H}_{s}=$ state matrices obtained from application of the FEM; $\mathbf{F}_{s}^{p}, \mathbf{F}_{s}^{p v X}$ and $\mathbf{F}_{s}^{c n p}=$ matrices associated with $\mathbf{L}_{s}^{p}, \mathbf{L}_{s}^{p v X}$ and $\mathbf{L}_{s}^{c n p}$, respectively; $\mathbf{b}_{s}$ and $\mathbf{d}_{\mathrm{s}}=$ right-hand side constant vectors; $\mathbf{L}_{s}^{o}$ and $\mathbf{C}_{s}^{o}=$ vectors of in-stream COD and DO concentrations at loading points and/or stream junctions, respectively; $\mathbf{L}_{s}^{o u}$ and $\mathbf{C}_{s}{ }^{o l}=$ vectors of limitations of WQSs for COD and DO concentrations, $L_{s}^{o u}$ and $C_{s}^{o l}$, respectively; $\mathbf{U}_{s}^{o+}$ and $\mathbf{V}_{s}{ }^{o+}=$ vectors of violated deviations of COD and DO concentrations from WQSs, $U_{i s}{ }^{o+}\left(\mathrm{M} / \mathrm{L}^{3}\right)$ and $V_{i s}{ }^{o+}\left(\mathrm{M} / \mathrm{L}^{3}\right)$, respectively; $\mathbf{U}_{\mathrm{s}}{ }^{\mathrm{o}-}$ and $\mathbf{V}_{\mathrm{s}}{ }^{\mathrm{o}-}$ $=$ vectors of surplus deviations of COD and DO concentrations from WQSs, $U_{i s}^{o-}\left(\mathrm{M} / \mathrm{L}^{3}\right)$ and $V_{i s}^{o-}$ $\left(\mathrm{M} / \mathrm{L}^{3}\right)$, respectively; $L_{s}{ }^{d}$ and $\mathrm{C}_{\mathrm{s}}{ }^{d}=\mathrm{COD}$ and DO concentrations at the downstream end of the river $\left(\mathrm{M} / \mathrm{L}^{3}\right)$, respectively; $L_{s}^{d u}=$ upper limit for $L_{s}^{d} ; C_{s}^{d l}=$ lower limit for $C_{s}{ }^{d} ; \mathbf{L}_{s}^{p l}$ and $\mathbf{L}_{s}^{p u}=$ vectors of lower and upper COD limits for effluent from $k$ th ITPS, $L_{k s}^{p l}$ and $L_{k s}^{p u}$, respectively; $\mathbf{L}_{s}^{p v X l}$ and $\mathbf{L}_{s}^{p v X u}$ $=$ vectors of lower and upper COD limits collected effluent from CTPS $X$ in $j$ th subcatchment, $L_{j s}^{p v X l}$ and $L_{j s}^{p v X u}$, respectively; $r^{c n p l}$ and $r^{c n p u}=$ lower and upper limits for the rate of optimal to current CNPS-born COD loads, respectively; $L O_{j}^{c n p}=$ current CNPS-born COD load arriving at the outlet of $j$ th subcatchment; $L O^{p l}, L O^{p v X l}$ and $L O^{c n p l}=$ lower limits for expected total COD loads from ITPSs, CTPSs $X$ and CNPSs, respectively; $y_{s}^{+}, y_{s}^{-}$and $w=$ supplementary variables; and $\varepsilon_{j}=$ bounding parameter in the $\varepsilon$-constraint $(j=2,3,4)$.

The total controllable load is the sum of all the loads from PSs and CNPSs, as expressed in Eq. (23). It is noted that temporal variations of lateral discharges from CNPSs, $q_{j s}{ }^{c n p}$, are considered in 
the scenarios, while those from all the PSs are treated as constant. Hard constraints (or constraints with no relaxation) on WQS may fail to produce feasible solutions of the model. Therefore WQSs are expressed as equality constraints in Eqs. (6) and (7) where violations of WQSs are permitted. Objective functions $f_{3}$ and $f_{4}$ appropriately penalize the constraint violations which are realized by giving smaller $\varepsilon_{3}$ and $\varepsilon_{4}$ values. Despite no existence of institutional constraints on the wasteloads from CNPSs, Eq. (11) is imposed to restrict extraordinary deviations of their loads from the current loading levels. Specifications of the lower limits of expected total COD loads from ITPSs, CTPSs and CNPSs, expressed by Eqs. (12) to (14), help effectively obtain the management alternatives that would satisfy the decision-maker's preferences with respect to the respective total allowable loads. Eqs. (16) and (17) are introduced to rewrite Eq. (20) as $f_{2}=w$, so that the whole problem can be handled as a linear programming one.

A prime objective of the model is to minimize $f_{1}$ so that the expected total controllable COD loading can be maximized. Other objective functions are minimized in order to explore noninferior solutions that are robust against (i.e., less sensitive to) the uncertainties of input parameters. Minimizing $f_{2}$ results in diminishing monthly variations of total loading, which leads to a 'solution robust' solution. Minimizing $f_{3}$ and $f_{4}$ keeps the river water quality close to the WQSs and a 'model robust' solution is generated. Since those objectives are generally in conflict, the $\varepsilon$-constraints in Eq. (15) are used to achieve the preferred level of $f_{j}$ by giving a suitable $\varepsilon_{j}$ (for $j=2,3$ or 4 ). Holding the equalities in Eq. (15) is a sufficient condition for judging that the obtained solution is noninferior. By solving the $\varepsilon$-RO model (Eqs. (3)-(18)), which is reduced to a linear programming model, allocated COD concentrations $\left(L_{k s}^{p}, L_{j s}^{p v X}, L_{j s}^{c n p}\right)$ among pollutant sources at each scenario are procured.

Compared with our last $\varepsilon$-RO model (Kawachi and Maeda, 2004b), the modified $\varepsilon$-RO model presented here has more constraints, namely Eqs. (10)-(14) are added. Furthermore, controllable COD loadings to the river are thoroughly considered in this study, expressed in Eqs. (4) and (23), and thus the modified $\varepsilon$-RO model can efficiently provide more persuasive management alternatives.

\section{Application}

The $\varepsilon$-RO model (Eqs. (3) to (18)) is applied to a downstream part of the Yasu River, in Shiga Prefecture, Japan, in order to seek management alternatives for improving its current water quality. The selected part of the river $(18.6 \mathrm{~km})$ and its corresponding catchment $\left(89.6 \mathrm{~km}^{2}\right)$ are referred to as 'river reach' and 'catchment system', respectively. Dominant land use types in the catchment system are paddy field (18.0\%), upland crop field (1.0\%), city (20.1\%), forest (48.3\%) and golf link 
(2.7\%). The major part of the agricultural lands (i.e., paddy fields and upland crop fields) fringes the river in the central flat region of the catchment system (Fig. 2). The catchment system is divided into nine subcatchments as numbered in Fig. 3.

There are 74 industrial wastewater treatment plants (i.e., ITPSs) in total. The observed discharges and COD concentrations at every source are available for three fiscal years (1993 - 1995). There are no public treatment plants or night soil treatment facilities significantly affecting in-stream water quality in the river reach. Sources handled as CTPSs are only on-site domestic septic tanks which comprise 25 ITTs treating both night soil and household gray water and 16 STTs treating only night soil. The total population served by ITTs and the total discharges and COD loads from ITTs for the subcatchments are listed in Table 1. The same data is given for STTs in Table 2. Per capita daily discharge and COD loading are taken as $0.27 \mathrm{~m}^{3} /$ capita/day and $7.3 \mathrm{~g} /$ capita/day for ITT, and $0.27 \mathrm{~m}^{3} /$ capita/day and $25.3 \mathrm{~g} /$ capita/day for STT, respectively (Land Agency et al., 1999). Lateral discharges from CNPSs and forests into the Yasu River are estimated on the basis of a water balance using monthly river discharge data available at Yokotabashi and Hattoriohashi in 1990-1998 and other related inflow and outflow data. The forest-born COD loading is evaluated based on its well-standardized unit area loading of $51.4 \mathrm{~g} / \mathrm{ha}$ /day used exclusively in Shiga prefecture (Land Agency et al., 1999). Delineation of the subcatchment boundaries and identification of the wastewater outfalls are implemented in ArcView GIS 8.2, using DEM with a grid resolution of 50 $\mathrm{m} \times 50 \mathrm{~m}$, provided by the Japan Geological Survey Institute, and a digital topographic map.

The river reach is discretized into line elements with the nodes as depicted in Fig. 4, where locations of inflows and outflows are also shown, and $q_{l}^{p}(l=1,2, \cdots, 14)$ represent lateral wastewater discharges from ITPSs to the lth loading point. Lateral discharges $q_{j}^{c n p}, q_{j}^{p v 1}$ and $q_{j}^{p v 2}$ are those from CNPSs, ITTs and STTs in the $j$ th subcatchment, respectively. Considering the rapid and significant changes of flow and transport at the Ishibe diversion work located in the mid-course of the river, the river reach is divided into two sub-reaches, Sub-reaches 1 and 2, in order to implement flow analysis separately (Kawachi and Maeda, 2004b).

A set of twelve scenarios is provided to derive optimal strategies for water pollution control under hydro-environmental uncertainties. Key components of the scenario, i.e., $Q, L$, and $C$ at the upstream end of reach, $h$ at the downstream end of reach, $q_{j}^{c n p}(j=1,2, \cdots, 9), T, K_{1}$ and $K_{2}$, are summarized in Table 3. $Q, L, C$ and $h$ are monthly-observed values. Calibration of the COD and DO transport models is performed in each sub-reach under twelve scenarios to identify a deoxygenation coefficient $K_{1}$ and a reaeration coefficient $K_{2}$. It is noted that wastewater discharges from CNPSs are much larger than those from ITTs and STTs in all the subcatchments (see Tables 1, 2 and 3). The COD-based water quality standard for the river is specified as $L_{i s}{ }^{o u}=2.3(\mathrm{mg} / \mathrm{L})$ (Kawachi and Maeda, 2004b). As by the Basic Environmental Law, $C_{i s}{ }^{o l}=7.5(\mathrm{mg} / \mathrm{L})$ is specified as the lower 
limit of in-stream DO concentration. The limits $L_{s}^{d u}$ and $C_{s}^{d l}$ are identified with the averages of monthly observed COD and DO concentrations at Node 28, respectively, in order to keep at the very least the current level of water quality at the downstream end of the river reach. The lower limits, $L_{k s}{ }^{p l}, L_{j s}{ }^{p v l l}$ and $L_{j s}{ }^{p 2 l}$, are set at zero. The different upper limits $L_{k s}{ }^{p u}$ are given for different industrial wastewater treatment plants, based on the nationwide applied effluent standard (160 $\mathrm{mg} / \mathrm{L}$ ) and the local stringent add-on effluent standards classified by industry (Land Agency et al., 1999). The upper limits $L_{s}^{p v l u}$ and $L_{s}^{p v 2 u}$ are taken as $20 \mathrm{mg} / \mathrm{L}$, the local prefectural standard. Other parameters are prescribed as follows: $r^{c n p l}=0.5, r^{c n p u}=1.5, L O^{p l}=4.694 \mathrm{~g} / \mathrm{s}, L O^{p v l l}=0, L O^{p v 2 l}=0$ and $L O^{c n p l}=5.433 \mathrm{~g} / \mathrm{s}$. The values of $L O^{p l}$ and $L O^{c n p l}$ are equal to the current total loads from industrial wastewater treatment plants and CNPSs, respectively.

\section{Results and Discussion}

The $\varepsilon$-RO model which includes 2,521 variables and 3,169 constraints is solved using a Fortran program of the simplex method (Ibaraki and Fukushima, 1991). Referring to the four different alternatives to the current management policy, three optimized ( $<$ Solution $\mathrm{A}>,<$ Solution $\mathrm{B}>$ and $<$ Solution $\mathrm{C}>$ ) and one non-optimized (or speculative), implication of the $\varepsilon$-RO model is demonstrated. <Solution $\mathrm{A}>$ is that obtained from a set of Eqs. (3) to (18), dropping the $\varepsilon$-constraints of Eq. (15). $<$ Solution $\mathrm{B}>$ and $<$ Solution $\mathrm{C}>$ are fully optimized solutions taking $\left(\varepsilon_{2}, \varepsilon_{3}\right.$, $\left.\varepsilon_{4}\right)$ as $(0.1100,3.400,34.00)$ and $(0.1100,4.800,34.00)$, respectively, in order to differentiate optimal allocations by controlling WQS violations. The non-optimized management alternative presently considered is an easy example policy which speculatively forces violating PS discharges to reduce their current pollutant loads to specified limitation standards even though there are no assurances of effectively improving in-stream water qualities. For the violators (twelve industrial wastewater treatment plants and all the ITTs and STTs), therefore, their effluent COD concentrations are identified to specified limits in simulation practice for this alternative. Important attributes of the optimal solutions and the speculative and current management policies are summarized in Table 4 and Table 5. Profiles of the (expected) COD concentrations along the entire river reach, which result from optimal, speculatively reduced and current COD loadings, are illustrated in Fig. 5. The profile of current COD concentration shown in Fig. 5 is estimated by solving the finite element model of COD transport with observed COD concentrations at upstream boundaries of the river reaches. The corresponding DO concentration profiles are not shown because of their indistinguishable differences between all the loading practices.

In $<$ Solution $\mathrm{A}>$, only maximization of total allowable COD load is considered, discarding the objectives $f_{j}(j=2,3$ and 4$)$ related to solution and model robustness. Thus the total allowable load 
is the highest and in particular the total load from CNPSs increases by $42 \%$ compared to the current load (Table 5). This, however, leads to water quality deterioration in the upstream part of the stream (Fig. 5).

$<$ Solution B $>$ features a stream water quality improvement of $6.5 \%$ (Table 4$)$. Notably however, all the loadings from ITTs and STTs need to be prevented at their sources to achieve the lowest level of in-stream COD concentration. $<$ Solution B $>$ results in satisfying the WQS at the end of the river reach as well, as shown in Table 4. Because of these characteristics, decision-makers in favor of improving in-stream water quality would most likely employ $<$ Solution $\mathrm{B}>$ as a management alternative. It is also noteworthy that in $<$ Solution $\mathrm{B}>$ the magnitude of violation of WQS for COD concentration can be kept small along the whole river reach with less load reduction, compared to the noninferior solutions produced in our last study (Kawachi and Maeda, 2004b). Clearly, this is a result of additionally controlling wasteloads from CNPSs and non-industrial point sources in this study.

$<$ Solution $\mathrm{C}>$ is particularly remarkable because it improves stream water quality by $3.5 \%$ despite a $2.1 \%$ increase of total allowable COD load. The in-stream COD concentration at every node in $<$ Solution $\mathrm{C}>$ is lower than the current one, as shown in Fig. 5. This solution suggests that loadings from ITTs and STTs should be reduced, while those from CNPSs can be increased by $16 \%$ (Table 5). Reallocation of COD load based on this solution makes it possible to effectively improve river water quality.

The speculative management alternative results in improving stream water quality by only $1.9 \%$ although the total allowable load decreases by $11 \%$ (Table 4 ). This fact indicates that such an exclusive and speculative measure only for PSs, likely to be practically employed, is quite ineffective and inferior to the optimal solutions provided by the $\varepsilon$-RO model.

Reallocation of the total allowable load among the pollutant sources in accordance with the noninferior solutions could be a valid way to restore the river water quality environment. Fig. 6 illustrates the optimal expected COD loads allocated to ITPSs in $<$ Solution $\mathrm{C}>$. If the solution is to be employed as a management policy, 21 out of 74 ITPSs will need to reduce their current COD levels to the required ones. $31 \%$ of the ITPSs that are located upstream from the Ishibe diversion work are then required to implement a load reduction to a greater or lesser degree.

In Fig. 7, optimally allocated CNPSs-, ITTs- and STTs-born COD loads in $<$ Solution C $>$ are compared with the non-optimized current load on a subcatchment basis. Optimal load from a subcatchment is prevented from drastically changing by appropriately predetermining $r^{c n p l}$ and $r^{c n p u}$ in Eq. (11). The solution requires that the subcatchment 2, located upstream, should reduce its current CNPSs-born COD load. Fig. 6 explicitly specifies the subcatchments where wasteloads from CNPSs, ITTs and STTs should be decreased or can be increased, and gives the amount of load 
to be changed as well.

\section{Conclusions}

A stochastic multiobjective programming model, an $\varepsilon$-RO model as a simulation-optimization model with embedding approach, has been developed for river water quality management under hydro-environmental uncertainty. The model is a hybrid of the $\varepsilon$-constraint method and the RO framework which depresses the high sensitivity of the model to the input data uncertainties by introducing a plausible set of scenarios. By virtue of the $\varepsilon$-constraint method, the model is capable of producing only such noninferior solutions (or management alternatives) as are worthy of discussion in a decision-making process to optimally control COD loads discharged from pollutant sources. Versatility and enhanced ability of the model lie in the facts that all kinds of PSs and NPSs excepting forests can be treated as controllable, and that FEM is employed for approximations to coupled COD and DO transport equations. Application to a branched and/or looped river system is also straightforward. The $\varepsilon$-RO model developed could thus be a viable alternative to the conventional management models.

The use of GIS is vital for the model as can be seen from the demonstrative optimization practices for the Yasu River. Operation of the model with the aid of the ArcView GIS has proved that there is indeed an alternative management strategy to improve in-stream water quality as a whole while increasing the total load to the river. Inferiority of the speculative easy management, which requires depletion of PSs-born COD loadings to their standard limits, has also been verified in comparison with the optimized managements. Particular point sources or subcatchments that should decrease their COD loadings to the river, as well as the COD levels to be achieved there, can be elucidated by the model.

Application of the RO framework requires care in formulating objective functions and generating a set of hydro-environmental scenarios. Basic COD and DO transport equations are employed in this study as water quality models in the river of interest. In the future, embedding advanced water quality models in the $\varepsilon$-RO model would be needed. Imprecision in management objectives should also be addressed in the framework.

Modeling of the river water quality management intended for catchments is diversified into two types of modeling inter- and intra-catchment management problems that treat a catchment (or subcatchment) as lumped and distributed systems, respectively. The present $\varepsilon$-RO model is categorized as an inter-subcatchment model. The maximum allowable load allocated to the outlet of a subcatchment, obtained from the model, can be a major constraint (related to the water quality standard to be met) for the intra-subcatchment management model, which serves to reallocate this 
maximum load among the local dischargers distributed over the subcatchment. Development of such an intra-subcatchment model, to be embarked upon in future work, is needed for presenting limitary wasteloads to each of the local dischargers. Wasteload allocation on a local level will be in more serious conflict between agricultural and non-agricultural sectors, and/or between farmers. The common recognitions that agriculture significantly contributes to degradation of river water quality and that source-oriented water quality control is an urgent need will, however, require farmers to collaboratively take part in decision-making. Along this line, studies on making farming practices (e.g., land use, cropping pattern and fertilizer application) more environmentally friendly will have to be made in the framework of optimization as well.

\section{Acknowledgements}

The authors are grateful to the Department of Lake Biwa and the Environment and to the Department of Agricultural Policy and Fishery, Shiga Prefectural Government, Japan, for offering the GIS source data and the PS-related water quality data in the catchment of the Yasu River.

\section{References}

Alley, W. M. (1986). Regression approximations for transport model constraint sets in combined aquifer simulation-optimization studies. Water Resources Research, 22(4), 581-586.

Chang, N. B., Chen, H. W., Shaw, D. G., Yang, C. H. (1997). Water pollution control in river basin by interactive fuzzy interval multiobjective programming. Journal of Environmental Engineering, ASCE, 123(12), 1208-1216.

Chankong, V., Haimes, Y. Y. (1983). Multiobjective Decision Making: Theory and Methodology, North Holland, New York, 113-175.

Ejaz, M. S., Peralta, R. C. (1995). Modeling for optimal management of agricultural and domestic wastewater loading to streams. Water Resources Research, 31(4), 1087-1096.

Gharbi, A., Peralta, R.C. (1994). Integrated embedding optimization applied to Salt Lake valley aquifers. Water Resources Research, 30(3), 817-832.

Gorelick, S. M., Remson, I. (1982). Optimal location and management of waste disposal facilities affecting ground water quality. Water Resources Bulletin, 18(1), 43-51.

Hathhorn, W. E., Tung, Y. K. (1989). Bi-objective analysis of waste load allocation using fuzzy linear programming. Water Resources Management, 3, 243-257.

Ibaraki, T., Fukushima, M. (1991). Programming for Solving Optimization Problems. Iwanami, 39-58 (in Japanese). 
Jia, Y., Culver, T. B. (2006). Robust optimization for total maximum daily load allocations. Water Resources Research, 42, W02412, doi:10.1029/2005WR004079.

Kawachi, T., Maeda, S. (1999). Water pollution control in stream network by finite element and linear programming method. Proceedings of the Japan Academy, Ser. B, 75(6), 138-143.

Kawachi, T., Maeda, S. (2000). Robust optimization model for water quality management in river systems. Proceedings of the Japan Academy, Ser. B, 76(8), 112-117.

Kawachi, T., Maeda, S. (2004a). Optimal management of waste loading into a river system with nonpoint source pollutants. Proceedings of the Japan Academy, Ser. B, 80(8), 392-398.

Kawachi, T., Maeda, S. (2004b). Diagnostic appraisal of water quality and pollution control realities in Yasu River using GIS-aided epsilon robust optimization model. Proceedings of the Japan Academy, Ser. B, 80(8), 399-405.

Land Agency and Other Water-related Agencies/Ministries of Japan (1999). Comprehensive Investigations for Conservation of Lake Biwa. p.97 (In Japanese).

Maeda, S., Kawachi, T. (2001). $\varepsilon$-Constraint approach for robust optimization of wasteload allocation in river systems. Transactions of the Japanese Society of Irrigation, Drainage and Reclamation Engineering, 215, 117-124.

Maeda, S., Kawachi, T., Okumura, H. (2000). Robust optimization of river water quality management. Transactions of the Japanese Society of Irrigation, Drainage and Reclamation Engineering, 207, 77-82.

Mujumdar, P. P., Sasikumar, K. (2002). A fuzzy risk approach for seasonal water quality management of a river system. Water Resources Research, 38(1), doi:10.1029/2000WR000126.

Mulvey, J. M., Vanderbei, R. J., Zenios, S. A. (1995). Robust optimization of large-scale systems. Operations Research, 43(2), 264-281.

Peralta, R. C., Hegazy, M. A., Musharrafieh, G. R. (1994). Preventing pesticide contamination of groundwater while maximizing irrigation crop yield. Water Resources Research, 30(11), 3183-3193.

Takyi, A. K., Lence, B. J. (1999). Surface water quality management using a multiple-realization chance constraint method. Water Resources Research, 35(5), 1657-1670.

Unami, K. (1998). Optimization and Control of Water Conveyance/Storage Systems. Ph. D. thesis, Kyoto University, Kyoto, 14-18.

Unami, K., Kawachi, T., Okumura, H., Hiramatsu, K. (1996). Numerical model of pseudo steady flows in estuarine open channel networks using finite volume and finite element methods. In: Benkhaldoun, F., Vilsmeier, R. (Eds.), Finite Volumes for Complex Applications. Hermes, pp.563-570. 
Table 1 Wastewaters and COD loads from ITTs.

\begin{tabular}{cccc}
\hline $\begin{array}{c}\text { Subcatchment } \\
j\end{array}$ & $\begin{array}{c}\text { Population } \\
(\mathrm{cap})\end{array}$ & $\begin{array}{c}\text { Discharge } \\
\left(\mathrm{m}^{3} / \mathrm{s}\right)\end{array}$ & $\begin{array}{c}\text { COD Load } \\
(\mathrm{g} / \mathrm{s})\end{array}$ \\
\hline 1 & 1,176 & 0.00368 & 0.09936 \\
2 & 4,310 & 0.01347 & 0.36416 \\
3 & 266 & 0.00083 & 0.02248 \\
4 & 3 & 0.00001 & 0.00025 \\
5 & 32 & 0.00010 & 0.00270 \\
6 & 9 & 0.00003 & 0.00076 \\
7 & 13 & 0.00004 & 0.00110 \\
9 & 4 & 0.00001 & 0.00034
\end{tabular}

Table 2 Wastewaters and COD loads from STTs.

\begin{tabular}{cccc}
\hline $\begin{array}{c}\text { Subcatchment } \\
j\end{array}$ & $\begin{array}{c}\text { Population } \\
(\text { cap })\end{array}$ & $\begin{array}{c}\text { Discharge } \\
\left(\mathrm{m}^{3} / \mathrm{s}\right)\end{array}$ & $\begin{array}{c}\text { COD Load } \\
(\mathrm{g} / \mathrm{s})\end{array}$ \\
\hline 1 & 557 & 0.00174 & 0.16310 \\
2 & 671 & 0.00210 & 0.19649 \\
3 & 74 & 0.00023 & 0.02167 \\
5 & 8 & 0.00003 & 0.00234 \\
7 & 54 & 0.00017 & 0.01581 \\
\hline
\end{tabular}


Table 3 Key parameters of scenarios (Min.: Minimum; Max.: Maximum; $R 1$ : Sub-reach 1; $R 2$ : Sub-reach 2).

\begin{tabular}{llccc}
\hline Sub-reach 1 & & Min. & Max. & Mean \\
\hline Yokotabashi & $Q_{1}\left(\mathrm{~m}^{3} / \mathrm{s}\right)$ & 3.96 & 11.56 & 6.80 \\
& $L_{1}(\mathrm{mg} / \mathrm{L})$ & 1.77 & 3.14 & 2.37 \\
& $C_{1}(\mathrm{mg} / \mathrm{L})$ & 8.54 & 12.41 & 10.33 \\
\hline Ishibe & $h_{16}(\mathrm{~m})$ & 0.37 & 0.61 & 0.47 \\
\hline Subcatchment & $q_{1}{ }^{c n p}\left(\mathrm{~m}^{3} / \mathrm{s}\right)$ & 0.0091 & 0.2428 & 0.1041 \\
outlets & $q_{2}{ }^{c n p}\left(\mathrm{~m}^{3} / \mathrm{s}\right)$ & 0.0411 & 1.0985 & 0.4712 \\
& $q_{3}{ }^{c n p}\left(\mathrm{~m}^{3} / \mathrm{s}\right)$ & 0.0164 & 0.4370 & 0.1874 \\
& $q_{4}{ }^{c n p}\left(\mathrm{~m}^{3} / \mathrm{s}\right)$ & 0.0033 & 0.0874 & 0.0375 \\
& $q_{5}{ }^{c n p}\left(\mathrm{~m}^{3} / \mathrm{s}\right)$ & 0.0025 & 0.0659 & 0.0283 \\
& $q_{6}{ }^{c n p}\left(\mathrm{~m}^{3} / \mathrm{s}\right)$ & 0.0218 & 0.5825 & 0.2498 \\
& $q_{7}{ }^{c n p}\left(\mathrm{~m}^{3} / \mathrm{s}\right)$ & 0.0034 & 0.0906 & 0.0389 \\
\hline Whole & $T^{R 1}\left({ }^{\circ} \mathrm{C}\right)$ & 5.2 & 25.9 & 15.5 \\
reach & $K_{1}{ }^{R 1}(1 / \mathrm{day})$ & 0.00 & 12.7 & 3.70 \\
& $K_{2}{ }^{R 1}(1 / \mathrm{day})$ & 0.01 & 3.55 & 2.13 \\
\hline \hline Sub-reach 2 & & Min. & Max. & Mean \\
\hline Ishibe & $Q_{17}\left(\mathrm{~m}^{3} / \mathrm{s}\right)$ & 1.66 & 12.42 & 5.37 \\
& $L_{17}(\mathrm{mg} / \mathrm{L})$ & 2.24 & 3.64 & 2.84 \\
& $C_{17}(\mathrm{mg} / \mathrm{L})$ & 7.88 & 12.02 & 10.11 \\
\hline Hattoriohashi & $h_{28}(\mathrm{~m})$ & 0.26 & 0.58 & 0.39 \\
\hline Subcatchment & $q_{8}{ }^{c n p}\left(\mathrm{~m}^{3} / \mathrm{s}\right)$ & 0.0212 & 0.5652 & 0.2424 \\
outlets & $q_{9}{ }^{c n p}\left(\mathrm{~m}^{3} / \mathrm{s}\right)$ & 0.0121 & 0.3225 & 0.1383 \\
\hline Whole & $T^{R 2}\left({ }^{\circ} \mathrm{C}\right)$ & 5.4 & 27.1 & 16.0 \\
reach & $K_{1}{ }^{R 2}(1 / \mathrm{day})$ & 1.49 & 9.02 & 4.58 \\
& $K_{2}{ }^{R 2}(1 /$ day $)$ & 0.64 & 3.22 & 1.63 \\
\hline & & & & \\
\hline & & &
\end{tabular}

Table 4 Key attributes of results of optimized, speculative and current wasteload managements.

\begin{tabular}{cccc}
\hline & $\begin{array}{c}\text { Expected COD } \\
\text { concentration } \\
\text { in river }(\mathrm{mg} / \mathrm{L})\end{array}$ & $\begin{array}{c}\text { Expected COD concentration } \\
\text { at end of river reach }(\mathrm{mg} / \mathrm{L})\end{array}$ & $\begin{array}{c}\text { Total controllable } \\
\text { loads }(\mathrm{g} / \mathrm{s})\end{array}$ \\
\hline Solution A & 2.803 & 2.260 & 13.017 \\
Solution B & 2.490 & 2.284 & 10.146 \\
Solution C & 2.568 & 2.344 & 11.252 \\
\hline Speculative & 2.612 & 2.335 & 9.785 \\
\hline Current & 2.662 & 2.357 & 11.018 \\
\hline
\end{tabular}


Table 5 Total loads allocated to classified pollutant sources.

\begin{tabular}{ccccc}
\hline & ITPSs $(\mathrm{g} / \mathrm{s})$ & \multicolumn{2}{c}{ CTPSs $(\mathrm{g} / \mathrm{s})$} & \multirow{2}{*}{ CNPSs $(\mathrm{g} / \mathrm{s})$} \\
\cline { 2 - 4 } & Industrial T.P. & ITTs & STTs & \\
\hline Solution A & 4.841 & 0.363 & 0.085 & 7.727 \\
Solution B & 4.694 & 0.017 & 0.003 & 5.433 \\
Solution C & 4.694 & 0.240 & 0.032 & 6.286 \\
\hline Speculative & 3.903 & 0.363 & 0.085 & 5.433 \\
\hline \hline Current & 4.694 & 0.491 & 0.399 & 5.433 \\
\hline
\end{tabular}


- Individually treated PSs (ITPSs) (Industrial treatment plant, Public treatment plant, Night soil treatment facility)

- Collectively treated PSs (CTPSs) (Integrated treatment tank (ITT), Single treatment tank (STT), Community treatment plant)

- Controllable nonpoint sources (CNPSs) (Agricultural land, City, Golf link)

\section{Controllable}

Fig. 1. Classified pollutant sources.

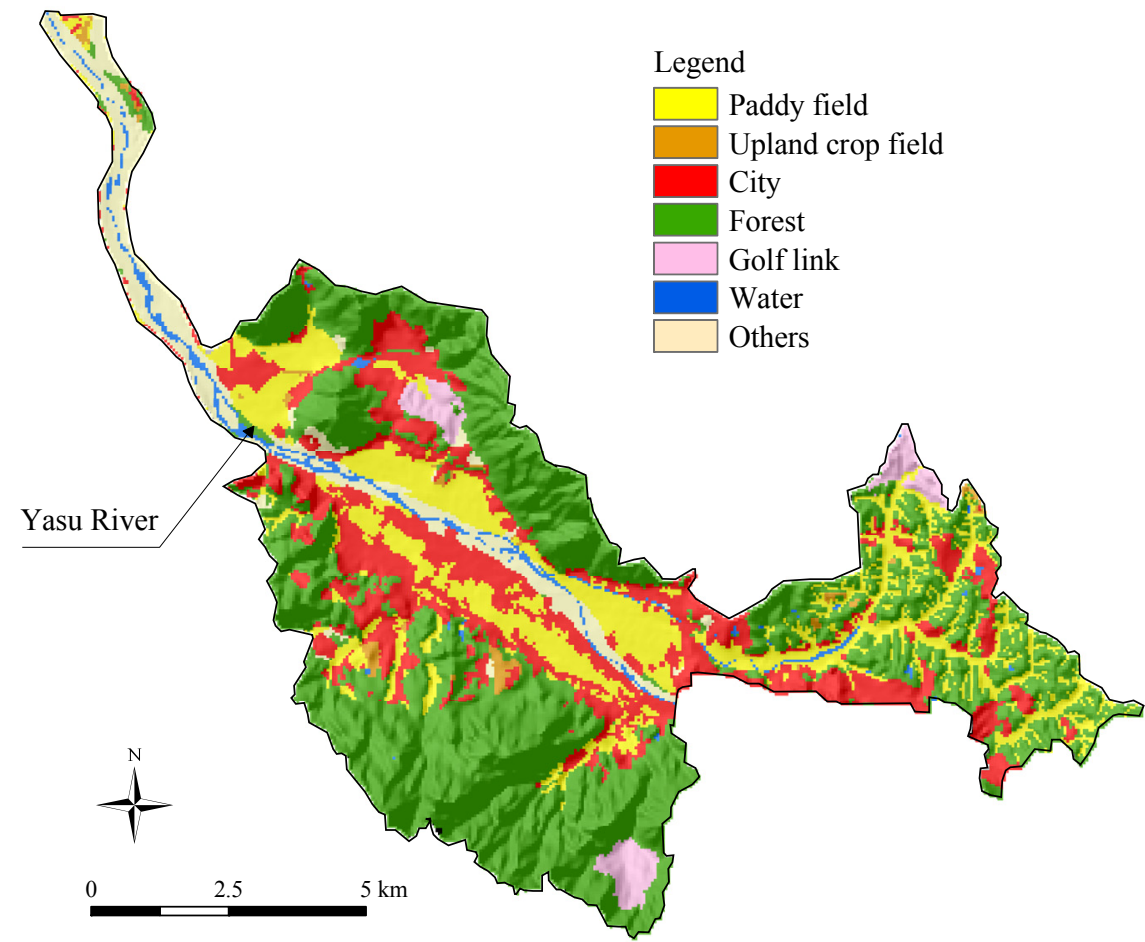

Fig. 2. Land use in catchment system. 
Hattoriohashi (Downstream end)

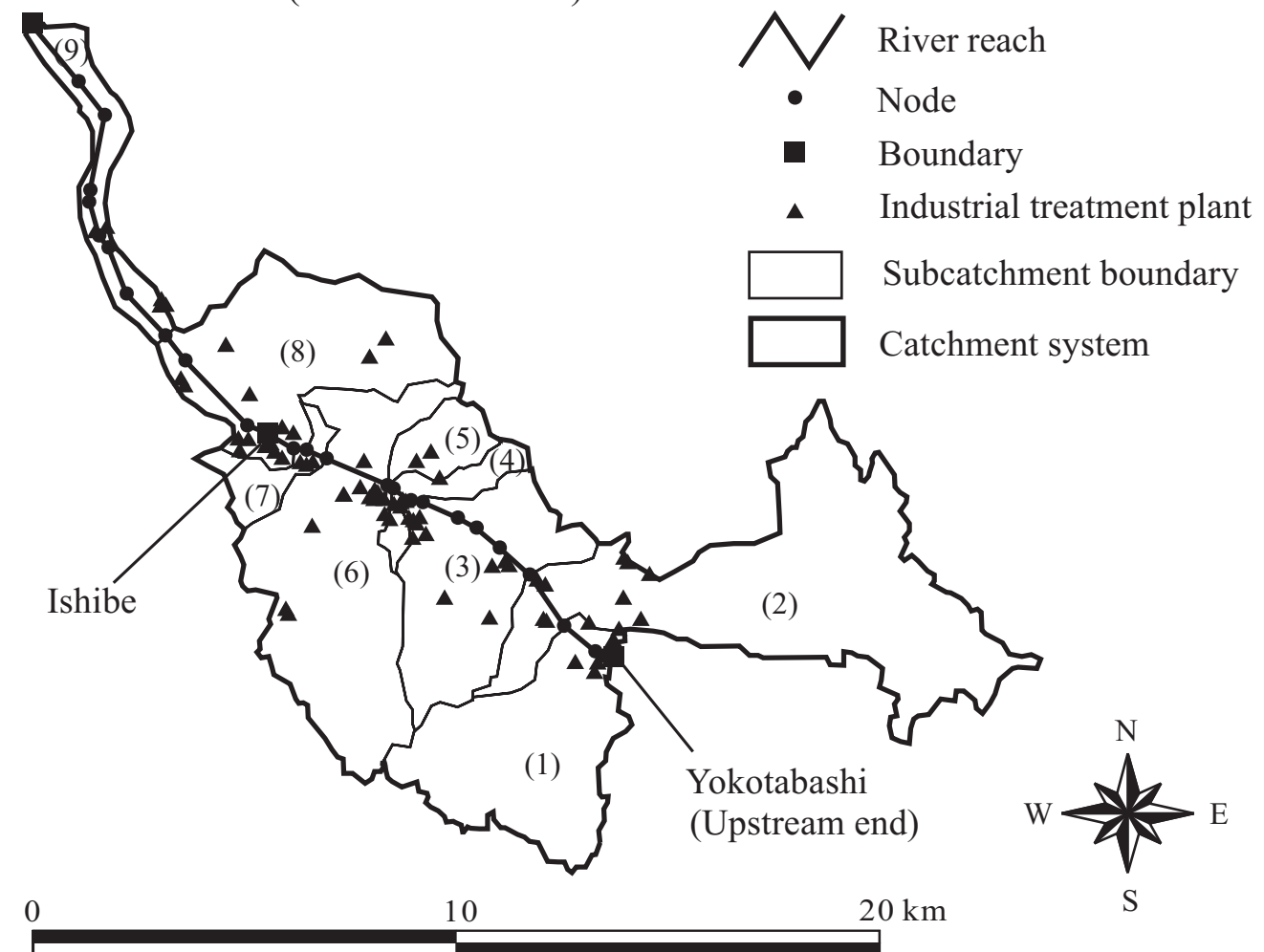

Fig. 3. River reach, plants and subcatchments numbered as (1), (2), $\cdots,(9)$. 


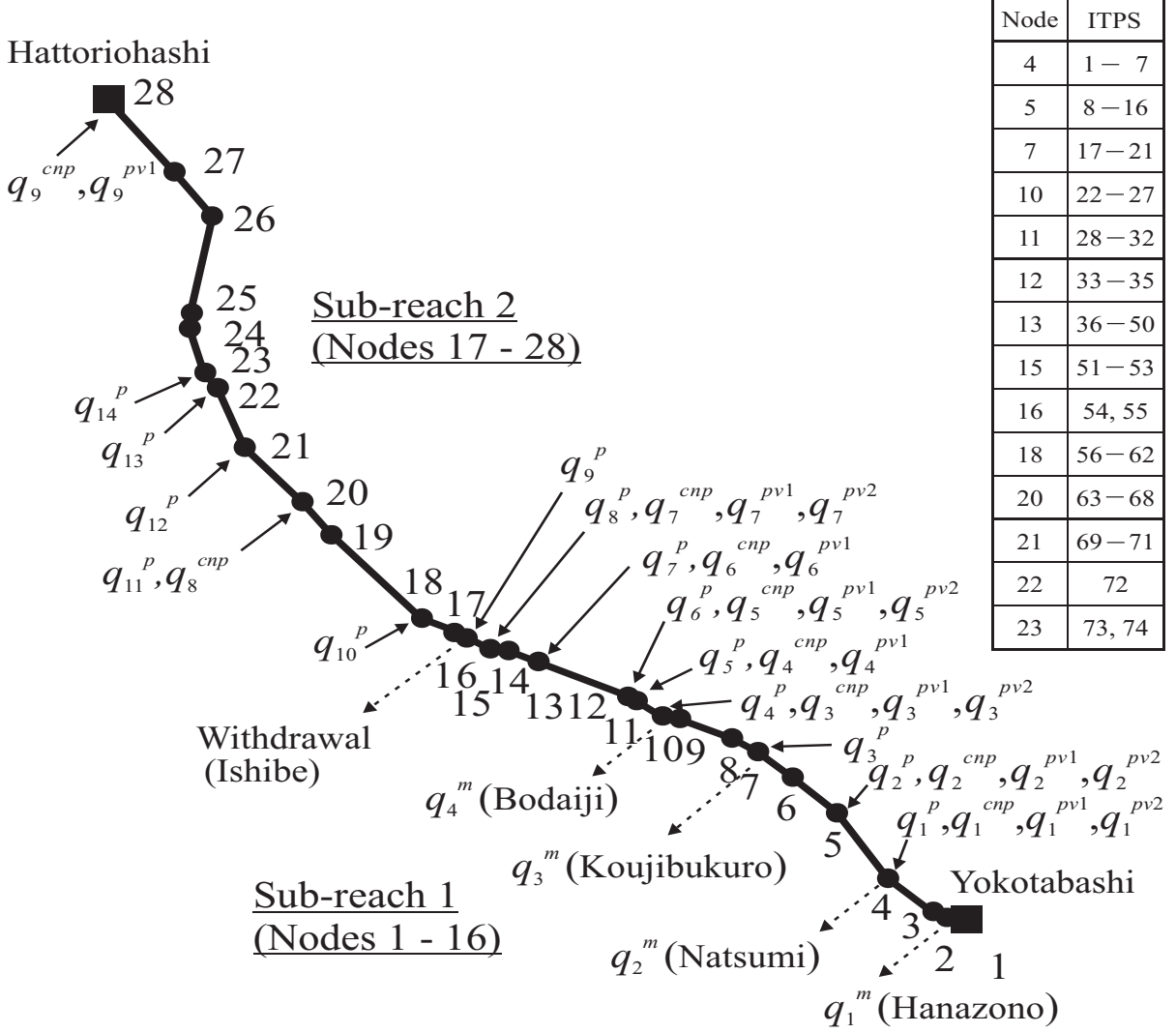

Fig. 4. Inflow/outflow locations (nodes), and nodes receiving effluents from treatment plants for ITPSs. 


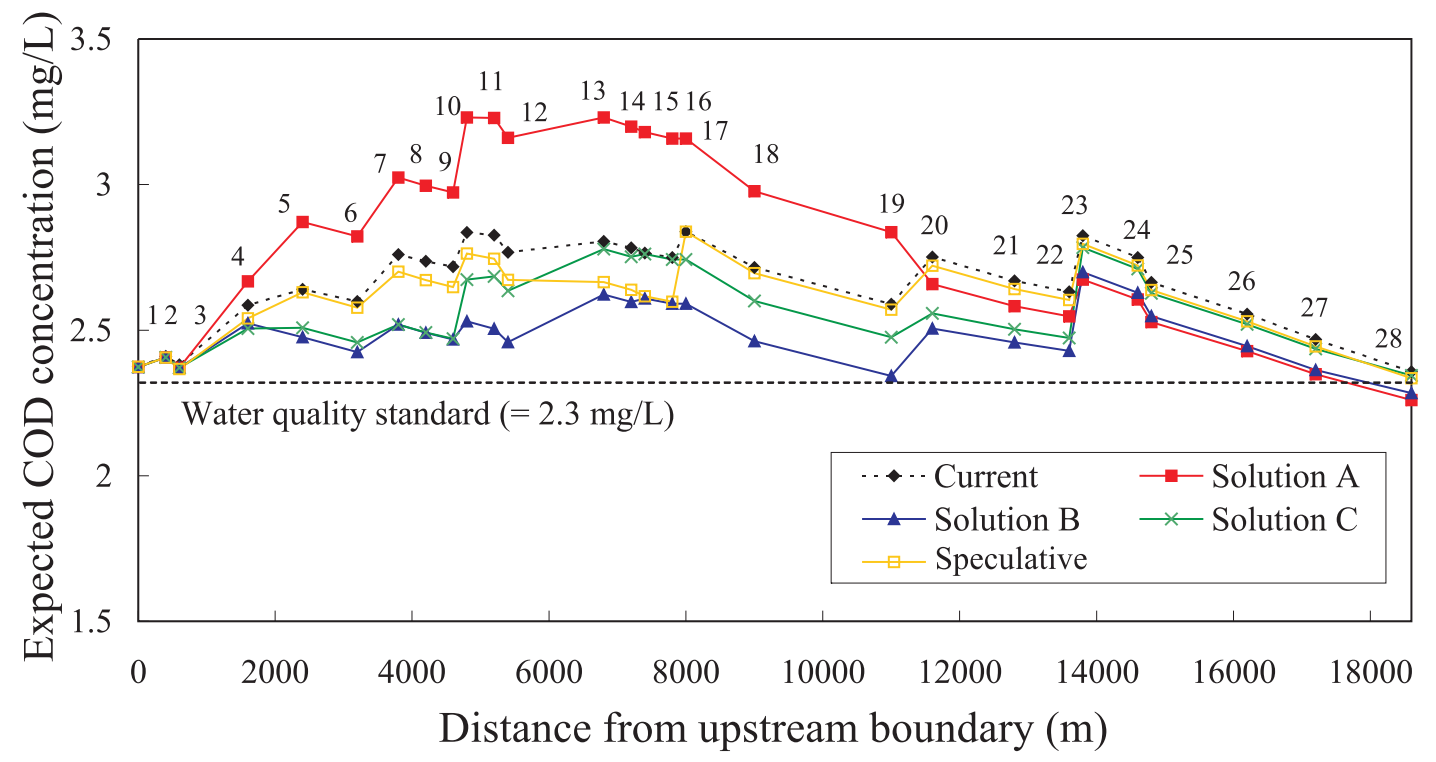

Fig. 5. Expected COD concentration profiles (with nodal numbers of $1,2, \cdots, 28$ ).

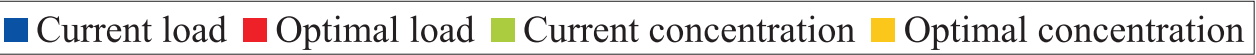

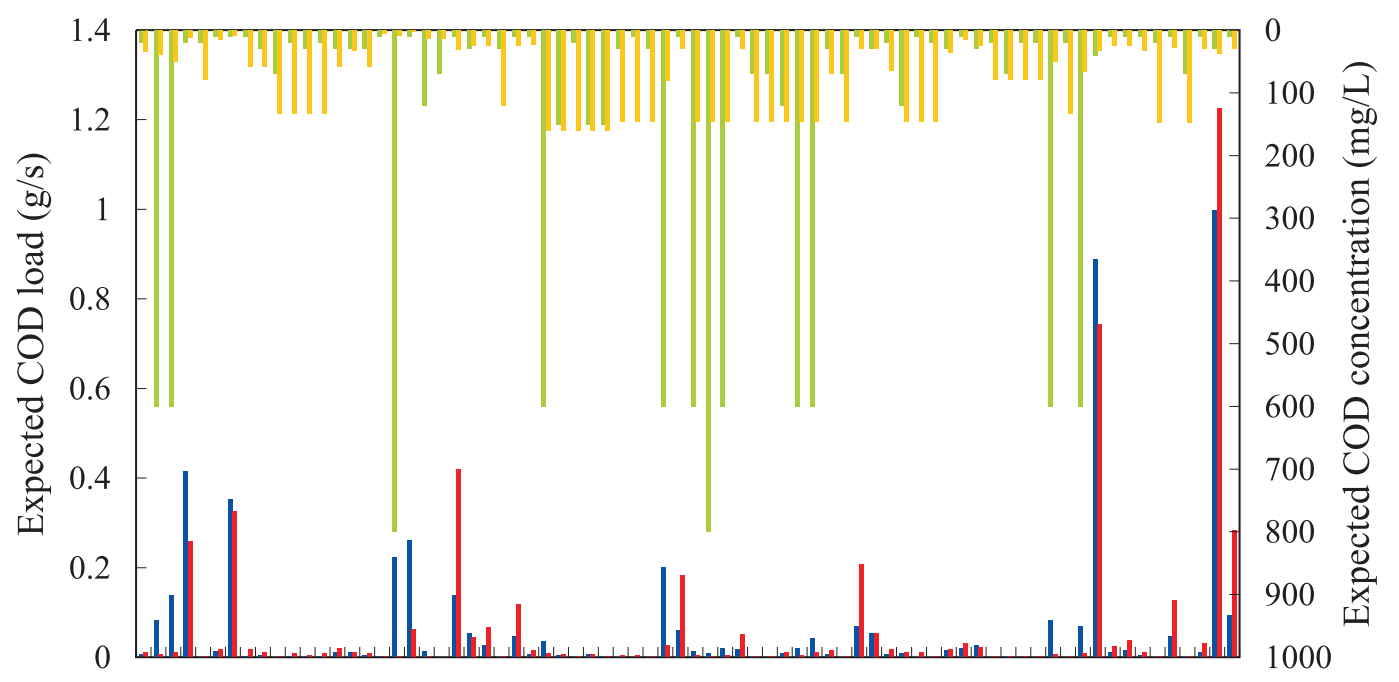

$144 \quad 710131619222528313437404346495255586164677073$

ID of industrial treatment plant

Fig. 6. Optimal COD loads and optimal COD concentrations of effluents from industrial treatment plants in $<$ Solution $\mathrm{C}>$. 


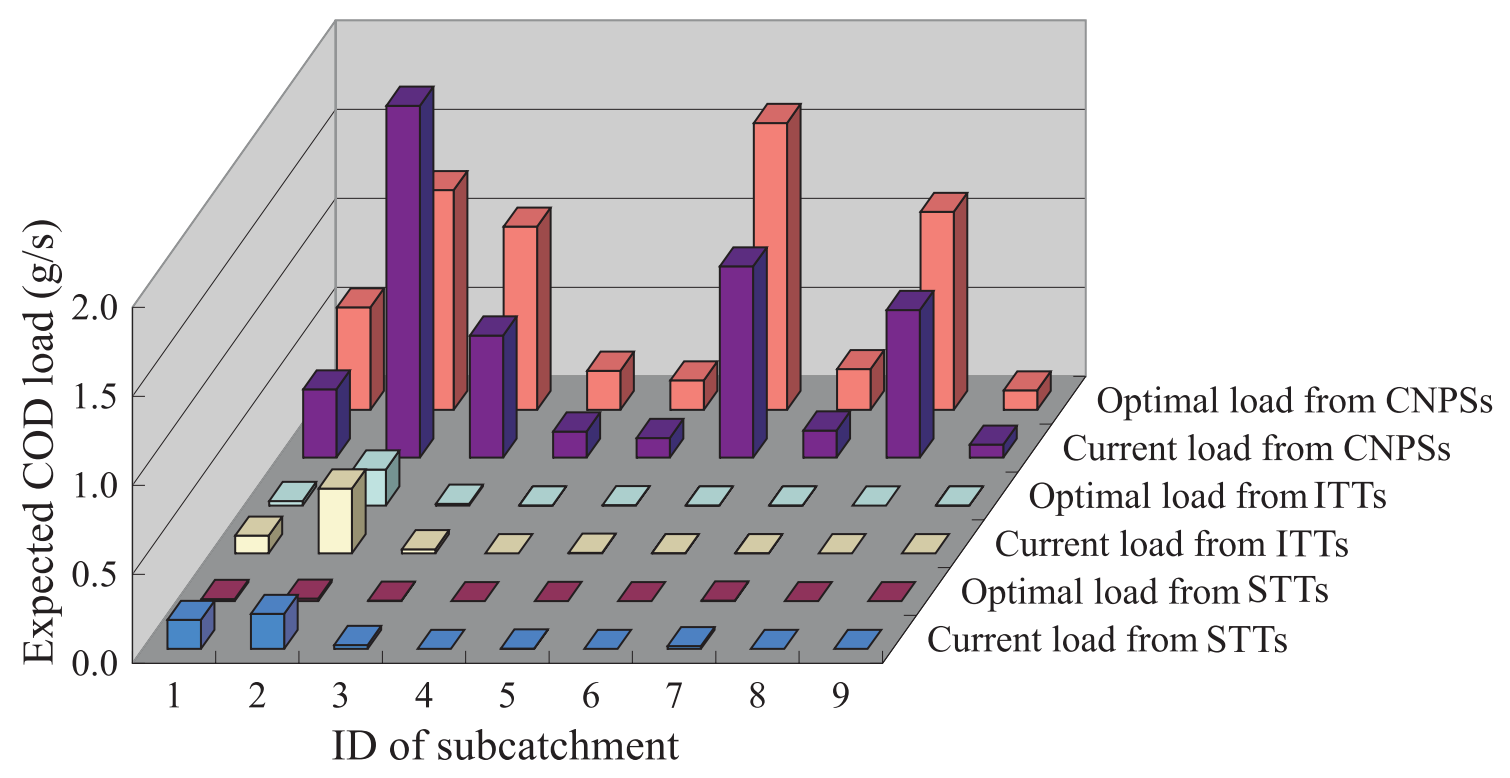

Fig. 7. Optimal COD loads allocated to CNPSs, ITTs and STTs in $<$ Solution C $>$. 